\title{
Susceptibility of ferrets, cats, dogs, and other domesticated animals to SARS-coronavirus 2
}

\author{
Jianzhong Shi' ${ }^{1 *}$, Zhiyuan Wen ${ }^{1 *}$, Gongxun Zhong1*, Huanliang Yang1*, Chong Wang1*, Baoying \\ Huang ${ }^{2 *}$, Renqiang Liu', Xijun He ${ }^{3}$, Lei Shuai', Ziruo Sun', Yubo Zhao', Peipei Liu' ${ }^{2}$, Libin Liang', \\ Pengfei Cui', Jinliang Wang ${ }^{1}$, Xianfeng Zhang ${ }^{3}$, Yuntao Guan ${ }^{3}$, Wenjie Tan ${ }^{2}$, Guizhen Wu ${ }^{2}+$, Hualan \\ Chen $^{1} \uparrow$, Zhigao Bu ${ }^{1,3} \uparrow$ \\ 1State Key Laboratory of Veterinary Biotechnology, Harbin Veterinary Research Institute, Chinese Academy of Agricultural Sciences, Harbin 150069, People's Republic of \\ China. ${ }^{2}$ National Institute for Viral Disease Control and Prevention, China CDC, Beijing 102206, People's Republic of China. ${ }^{3}$ National High Containment Laboratory for \\ Animal Diseases Control and Prevention, Harbin 150069, People's Republic of China. \\ *These authors contributed equally to this work. \\ †Corresponding author. Email: buzhigao@caas.cn (Z.B.); chenhualan@caas.cn (H.C.); wugz@ivdc.chinacdc.cn (G.W.)
}

Severe acute respiratory syndrome coronavirus 2 (SARS-CoV-2) causes the infectious disease COVID-19, which was first reported in Wuhan, China in December, 2019. Despite the tremendous efforts to control the disease, COVID-19 has now spread to over 100 countries and caused a global pandemic. SARS-CoV-2 is thought to have originated in bats; however, the intermediate animal sources of the virus are completely unknown. Here, we investigated the susceptibility of ferrets and animals in close contact with humans to SARS-CoV-2. We found that SARS-CoV-2 replicates poorly in dogs, pigs, chickens, and ducks, but ferrets and cats are permissive to infection. We found experimentally that cats are susceptible to airborne infection. Our study provides important insights into the animal models for SARS-CoV-2 and animal management for COVID-19 control.

In late December 2019, an unusual pneumonia emerged in humans in Wuhan, China, and rapidly spread internationally, raising global public health concerns. The causative pathogen was identified as a novel coronavirus (1-16) that was named Severe Acute Respiratory Syndrome Coronavirus 2 (SARSCoV-2) on the basis of a phylogenetic analysis of related coronaviruses by the Coronavirus Study Group of the International Committee on Virus Taxonomy (17); the disease it causes was subsequently designated COVID-19 by the World Health Organization (WHO). Despite tremendous efforts to control the COVID-19 outbreak, the disease is still spreading. As of March 11, 2020, SARS-CoV-2 infections have been reported in more than 100 countries, and 118,326 human cases have been confirmed, with 4,292 fatalities (18). COVID-19 has now been announced as a pandemic by WHO.

Although SARS-CoV-2 shares $96.2 \%$ identity at the nucleotide level with the coronavirus RaTG13, which was detected in horseshoe bats (Rhinolophus spp) in Yunnan province in 2013 (3), it has not previously been detected in humans or other animals. The emerging situation raises many urgent questions. Could the widely disseminated viruses transmit to other animal species, which then become reservoirs of infection? The SARS-CoV-2 infection has a wide clinical spectrum in humans, from mild infection to death, but how does the virus behave in other animals? As efforts are made for vaccine and antiviral drug development, which animal(s) can be used most precisely to model the efficacy of such control measures in humans? To address these questions, we evaluated the susceptibility of different model laboratory animals, as well as companion and domestic animals to SARS-CoV-2.

All experiments with infectious SARS-CoV-2 were performed in the biosafety level 4 and animal biosafety level 4 facilities in the Harbin Veterinary Research Institute (HVRI) of the Chinese Academy of Agricultural Sciences (CAAS), which was approved for such use by the Ministry of Agriculture and Rural Affairs of China. Details of the biosafety and biosecurity measures taken are provided in the supplementary materials (19). The protocols for animal study and animal welfare were reviewed and approved by the Committee on the Ethics of Animal Experiments of the HVRI of CAAS (approval number 2020-01-01JiPi).

Ferrets are commonly used as an animal model for respiratory viruses that infected humans $(20-26)$. We therefore tested the susceptibility of SARS-CoV-2 in ferrets. Two viruses [SARS-CoV-2/F13/environment/2020/Wuhan, isolated from an environmental sample collected in the Huanan Seafood Market in Wuhan (F13-E), and SARS-CoV2/CTan/human/2020/Wuhan (CTan-H), isolated from a human patient] were used in this study. Pairs of ferrets were inoculated intranasally with $10^{5}$ plaque forming unit (PFU) of F13-E or CTan-H, respectively, and euthanized on day 4 postinoculation (p.i.). The nasal turbinate, soft palate, tonsils, 
trachea, lung, heart, liver, spleen, kidneys, pancreas, small intestine, and brain from each ferret were collected for viral RNA quantification by qPCR and virus titration in Vero E6 cells. Viral RNA (Fig. 1, A and B) and infectious virus were detected in the nasal turbinate, soft palate, and tonsils of all four ferrets inoculated with these two viruses, but was not detected in any other organs tested (Fig. 1, C and D). These results indicate that SARS-CoV-2 can replicate in the upper respiratory tract of ferrets, but its replication in other organs is undetectable.

To investigate the replication dynamics of these viruses in ferrets, groups of three animals were inoculated intranasally with $10^{5} \mathrm{PFU}$ of F13-E or CTan-H, and then placed in three separate cages within an isolator. Nasal washes and rectal swabs were collected on days $2,4,6,8$, and 10 p.i. from the ferrets for viral RNA detection and virus titration. Body temperatures and signs of disease were monitored for two weeks. As shown in Fig. 1, viral RNA was detected in the nasal washes on days $2,4,6$, and 8 p.i. in all six ferrets inoculated with the two viruses (Fig. 1, E and F). Viral RNA was also detected in some of the rectal swabs of the virus-inoculated ferrets although the copy numbers were notably lower than those in the nasal washes of these ferrets (fig. S1, A and C). Infectious virus was detected from the nasal washes of all ferrets (Fig. 1, G and $\mathrm{H}$ ), but not from the rectal swabs of any ferrets (fig. S1, B and D).

One ferret from each virus-inoculated group developed fever and loss of appetite on days 10 and 12 p.i., respectively. To investigate whether these symptoms were caused by virus replication in the lower respiratory tract, we euthanized the two ferrets on day 13 p.i., and collected their organs for viral RNA detection. However, viral RNA was not detected in any other tissues or organs of either ferret, except for a low copy number $\left(10^{5.4} \mathrm{copies} / \mathrm{g}\right)$ in the turbinate of the ferret inoculated with CTan-H (fig. S2). Pathological studies revealed severe lymphoplasmacytic perivasculitis and vasculitis, increased numbers of type II pneumocytes, macrophages, and neutrophils in the alveolar septa and alveolar lumen, and mild peribronchitis in the lungs of the two ferrets euthanized on day 13 p.i. (fig. S3). Antibodies against SARS-CoV-2 were detected in all of the ferrets by an ELISA and a neutralization assay, although the antibody titers of the two ferrets that were euthanized on day 13 p.i. were notably lower than those of the ferrets euthanized on day 20 p.i. (Fig. 1, I to L).

A virus attachment assay indicated that SARS-CoV-2 could attach to bronchiolar epithelial cells (fig. S4A) and some type II pneumocytes (fig. S4B) in the ferret lung. To further investigate whether SARS-CoV-2 replicates in the lungs of ferrets, we intratracheally inoculated eight ferrets with $10^{5}$ PFU of CTan-H, and euthanized two animals each on days 2, 4, 8, and 14 p.i. to look for viral RNA in the tissues and organs. Viral RNA was only detected in the nasal turbinate and soft palate of one of the two ferrets that were euthanized on days 2 and 4 p.i.; in the soft palate of one ferret and in the nasal turbinate, soft palate, tonsil, and trachea of the other ferret that were euthanized on day 8 p.i.; and was not detected in either of the two ferrets that were euthanized on day 14 p.i. (fig. S5). These results indicate that SARS-CoV-2 can replicate in the upper respiratory tract of ferrets for up to eight days, without causing severe disease or death.

Cats and dogs are in close contact with humans, and therefore it is important to understand their susceptibility to SARS-CoV-2 for COVID-19 control. We first investigated the replication of SARS-CoV-2 in cats. Seven subadult cats (aged 6-9 months, outbred domestic cats) were intranasally inoculated with $10^{5} \mathrm{PFU}$ of CTan-H. Two animals were scheduled to be euthanized on days 3 p.i. and 6 p.i., respectively, to evaluate viral replication in their organs. Three subadult cats were placed in separate cages within an isolator. To monitor respiratory droplet transmission, an uninfected cat was placed in a cage adjacent to each of the infected cats. It was difficult to perform regular nasal wash collection on the subadult cats because they were aggressive. To avoid possible injury, we only collected feces from these cats and checked for viral RNA in their organs after euthanasia.

Viral RNA was detected in the nasal turbinate of one animal, in the soft palates, tonsils, tracheas, lungs, and small intestine of both animals that were euthanized on day 3 p.i., (Fig. 2A). In the animals that were euthanized on day 6 p.i., viral RNA was detected in the nasal turbinates, soft palates, and tonsils of both animals, in the trachea of one animal, and in the small intestine of the other; however, viral RNA was not detected in any of the lung samples from either of these animals (Fig. 2C). Infectious virus was detected in the viral RNA-positive nasal turbinates, soft palates, tonsils, tracheas, lungs of these cats, but was not recovered from the viral RNApositive small intestine (Fig. 2, B and D)

In the transmission study, viral RNA was detected in the feces of two virus-inoculated subadult cats on day 3 p.i., and in all three virus-inoculated subadult cats on day 5 p.i. (Fig. 3A). Viral RNA was detected in the feces of one exposed cat on day 3 p.i. (Fig. 3A). The pair of subadult cats with viral RNA-positive feces were euthanized on day 11 p.i., and viral RNA was detected in the soft palate and tonsils of the virusinoculated animal and in the nasal turbinate, soft palate, tonsils, and trachea of the exposed animal (Fig. 3B), indicating that respiratory droplet transmission had occurred in this pair of cats. We euthanized the other pairs of animals on day 12 p.i., and viral RNA was detected in the tonsils of one virusinoculated subadult cat, in the nasal turbinate, soft palate, tonsils, and trachea of the other virus-inoculated subadult cat, but was not detected in any organs or tissues of the two exposed subadult cats (Fig. 3B). Antibodies against SARSCoV-2 were detected in all three virus-inoculated subadult 
cats and one exposed cat by use of an ELISA and neutralization assay (Fig. 3, C and D).

We replicated the replication and transmission studies in juvenile cats (aged 70-100 days) (Figs. 2, E to H, and 3, E to G, and fig. S6). Histopathologic studies performed on samples from the virus-inoculated juvenile cats that died or euthanized on day 3 p.i. revealed massive lesions in the nasal and tracheal mucosa epitheliums, and lungs (fig. S7). These results indicate that SARS-CoV-2 can replicate efficiently in cats, with younger cats being more permissive and, perhaps more importantly, the virus can transmit between cats via the airborne route.

We next investigated the replication and transmission of SARS-CoV-2 in dogs. Five 3-month-old beagles were intranasally inoculated with $10^{5}$ PFU of CTan-H, and housed with two uninoculated beagles in a room. Oropharyngeal and rectal swabs from each beagle were collected on days $2,4,6,8$, 10, 12, and 14 p.i., for viral RNA detection and virus titration in Vero E6 cells. Viral RNA was detected in the rectal swabs of two virus-inoculated dogs on day 2 p.i., and in the rectal swab of one dog on day 6 p.i. (Table 1). One dog that was viral RNA positive by its rectal swab on day 2 p.i. was euthanized on day 4 p.i., but viral RNA was not detected in any organs or tissues collected from this dog (fig. S8). Infectious virus was not detected in any swabs collected from these dogs. Sera were collected from all of the dogs on day 14 p.i. for antibody detection by use of an ELISA. Two virus-inoculated dogs seroconverted; the other two virus-inoculated dogs and the two contact dogs were all seronegative for SARS-CoV-2 according to the ELISA (Table 1 and fig. S9). These results indicate that dogs have low susceptibility to SARS-CoV-2.

We also investigated the susceptibility of pigs, chickens, and ducks to SARS-CoV-2 by using the same strategy as that used to assess dogs; however, viral RNA was not detected in any swabs collected from these virus-inoculated animals or from naïve contact animals (Table 1), and all of the animals were seronegative for SARS-CoV-2 when tested by using the ELISA with sera collected on day 14 p.i. (Table 1). These results indicate that pigs, chickens, and ducks are not susceptible to SARS-CoV-2.

In summary, we found that ferrets and cats are highly susceptible to SARS-CoV-2, dogs have low susceptibility, and livestock including pigs, chickens, and ducks are not susceptible to the virus.

Ferrets have frequently been used as an animal model for the study of human respiratory viruses (20-26). Unlike influenza viruses and other human SARS-coronavirus, which replicate in both the upper and lower respiratory tract of ferrets $(20,22-24,26,27)$, we found SARS-CoV-2 only replicates in the nasal turbinate, soft palate, and tonsils of ferrets. It may also replicate in the digestive tract, as viral RNA was detected in the rectal swabs of the virus-infected ferrets, but virus was not detected in lung lobes, even after the ferrets were intratracheally inoculated with the virus. It remains unclear whether the virus causes more severe disease in male ferrets than in female ferrets, as has been observed among humans $(13,28)$.

Several studies have reported that SARS-CoV-2 uses angiotensin-converting enzyme 2 (ACE2) as its receptor to enter cells $(3,29-31)$. ACE2 is mainly expressed in type II pneumocytes and serous epithelial cells of tracheo-bronchial submucosal glands in ferrets (25). Ferrets and cats have only two amino acid differences in the SARS-CoV-2 spike-contacting regions of ACE2 (table S1); therefore, the underlying mechanism that prevents the replication of SARS-CoV-2 in the lower respiratory tract of ferrets remains to be investigated. The fact that SARS-CoV-2 replicates efficiently in the upper respiratory tract of ferrets makes them a candidate animal model for evaluating antiviral drugs or vaccine candidates against COVID-19.

The cats we used in this study were outbred, and were susceptible to SARS-CoV-2, which replicated efficiently and transmitted to naïve cats. Cats in Wuhan have been reported to be seropositive for SARS-CoV-2 (32). Surveillance for SARS-CoV-2 in cats should be considered as an adjunct to elimination of COVID-19 in humans.

\section{REFERENCES AND NOTES}

1. L. Zou, F. Ruan, M. Huang, L. Liang, H. Huang, Z. Hong, J. Yu, M. Kang, Y. Song, J. Xia, Q. Guo, T. Song, J. He, H.-L. Yen, M. Peiris, J. Wu, SARS-CoV-2 Viral Load in Upper Respiratory Specimens of Infected Patients. N. Engl. J. Med. 382, 11771179 (2020). doi:10.1056/NEJMc2001737 Medline

2. N. Zhu, D. Zhang, W. Wang, X. Li, B. Yang, J. Song, X. Zhao, B. Huang, W. Shi, R. Lu, P. Niu, F. Zhan, X. Ma, D. Wang, W. Xu, G. Wu, G. F. Gao, W. Tan; China Novel Coronavirus Investigating and Research Team, A Novel Coronavirus from Patients with Pneumonia in China, 2019. N. Engl. J. Med. 382, 727-733 (2020). doi:10.1056/NEJMoa2001017 Medline

3. P. Zhou, X.-L. Yang, X.-G. Wang, B. Hu, L. Zhang, W. Zhang, H.-R. Si, Y. Zhu, B. Li, C.L. Huang, H.-D. Chen, J. Chen, Y. Luo, H. Guo, R.-D. Jiang, M.-Q. Liu, Y. Chen, X.-R Shen, X. Wang, X.-S. Zheng, K. Zhao, Q.-J. Chen, F. Deng, L.-L. Liu, B. Yan, F.-X. Zhan, Y.-Y. Wang, G.-F. Xiao, Z.-L. Shi, A pneumonia outbreak associated with a new coronavirus of probable bat origin. Nature 579, 270-273 (2020). doi:10.1038/s41586-020-2012-7 Medline

4. F. Wu, S. Zhao, B. Yu, Y.-M. Chen, W. Wang, Z.-G. Song, Y. Hu, Z.-W. Tao, J.-H. Tian, Y.-Y. Pei, M.-L. Yuan, Y.-L. Zhang, F.-H. Dai, Y. Liu, Q.-M. Wang, J.-J. Zheng, L. Xu, E. C. Holmes, Y.-Z. Zhang, A new coronavirus associated with human respiratory disease in China. Nature 579, 265-269 (2020). doi:10.1038/s41586-020-2008-3 Medline

5. A. Wu, Y. Peng, B. Huang, X. Ding, X. Wang, P. Niu, J. Meng, Z. Zhu, Z. Zhang, J. Wang, J. Sheng, L. Quan, Z. Xia, W. Tan, G. Cheng, T. Jiang, Genome Composition and Divergence of the Novel Coronavirus (2019-nCoV) Originating in China. Cell Host Microbe 27, 325-328 (2020). doi:10.1016/i.chom.2020.02.001 Medline

6. C. Wang, P. W. Horby, F. G. Hayden, G. F. Gao, A novel coronavirus outbreak of global health concern. Lancet 395, 470-473 (2020). doi:10.1016/S01406736(20)30185-9 Medline

7. Y. Pan, D. Zhang, P. Yang, L. L. M. Poon, Q. Wang, Viral load of SARS-CoV-2 in clinical samples. Lancet Infect. Dis. 20, 411-412 (2020). doi:10.1016/S14733099(20)30113-4 Medline

8. X. Pan, D. Chen, Y. Xia, X. Wu, T. Li, X. Ou, L. Zhou, J. Liu, Asymptomatic cases in a family cluster with SARS-CoV-2 infection. Lancet Infect. Dis. 20, 410-411 (2020) doi:10.1016/S1473-3099(20)30114-6 Medline

9. R. Lu, X. Zhao, J. Li, P. Niu, B. Yang, H. Wu, W. Wang, H. Song, B. Huang, N. Zhu, Y. 
Bi, X. Ma, F. Zhan, L. Wang, T. Hu, H. Zhou, Z. Hu, W. Zhou, L. Zhao, J. Chen, Y. Meng, J. Wang, Y. Lin, J. Yuan, Z. Xie, J. Ma, W. J. Liu, D. Wang, W. Xu, E. C. Holmes, G. F. Gao, G. Wu, W. Chen, W. Shi, W. Tan, Genomic characterisation and epidemiology of 2019 novel coronavirus: Implications for virus origins and receptor binding. Lancet 395, 565-574 (2020). doi:10.1016/S01406736(20)30251-8 Medline

10. P. Liu, X. Z. Tan, 2019 Novel Coronavirus (2019-nCoV) Pneumonia. Radiology 295, 19 (2020). doi:10.1148/radiol.2020200257 Medline

11. Q. Li, X. Guan, P. Wu, X. Wang, L. Zhou, Y. Tong, R. Ren, K. S. M. Leung, E. H. Y. Lau, J. Y. Wong, X. Xing, N. Xiang, Y. Wu, C. Li, Q. Chen, D. Li, T. Liu, J. Zhao, M. Liu, W. Tu, C. Chen, L. Jin, R. Yang, Q. Wang, S. Zhou, R. Wang, H. Liu, Y. Luo, Y. Liu, G. Shao, H. Li, Z. Tao, Y. Yang, Z. Deng, B. Liu, Z. Ma, Y. Zhang, G. Shi, T. T. Y. Lam, J. T. Wu, G. F. Gao, B. J. Cowling, B. Yang, G. M. Leung, Z. Feng, Early Transmission Dynamics in Wuhan, China, of Novel Coronavirus-Infected Pneumonia. N. Engl. J. Med. 382, 1199-1207 (2020). doi:10.1056/NEJMoa2001316 Medline

12. C. Huang, Y. Wang, X. Li, L. Ren, J. Zhao, Y. Hu, L. Zhang, G. Fan, J. Xu, X. Gu, Z. Cheng, T. Yu, J. Xia, Y. Wei, W. Wu, X. Xie, W. Yin, H. Li, M. Liu, Y. Xiao, H. Gao, L. Guo, J. Xie, G. Wang, R. Jiang, Z. Gao, Q. Jin, J. Wang, B. Cao, Clinical features of patients infected with 2019 novel coronavirus in Wuhan, China. Lancet 395, 497506 (2020). doi:10.1016/S0140-6736(20)30183-5 Medline

13. W. J. Guan, Z. Y. Ni, Y. Hu, W. H. Liang, C. Q. Ou, J. X. He, L. Liu, H. Shan, C. L. Lei, D. S. C. Hui, B. Du, L. J. Li, G. Zeng, K. Y. Yuen, R. C. Chen, C. L. Tang, T. Wang, P. Y. Chen, J. Xiang, S. Y. Li, J. L. Wang, Z. J. Liang, Y. X. Peng, L. Wei, Y. Liu, Y. H. Hu, P. Peng, J. M. Wang, J. Y. Liu, Z. Chen, G. Li, Z. J. Zheng, S. Q. Qiu, J. Luo, C. J. Ye, S. Y. Zhu, N. S. Zhong; China Medical Treatment Expert Group for Covid-19, Clinical Characteristics of Coronavirus Disease 2019 in China. N. Engl. J. Med. (2020). 10.1056/NEJMoa2002032 Medline

14. N. Chen, M. Zhou, X. Dong, J. Qu, F. Gong, Y. Han, Y. Qiu, J. Wang, Y. Liu, Y. Wei, J. Xia, T. Yu, X. Zhang, L. Zhang, Epidemiological and clinical characteristics of 99 cases of 2019 novel coronavirus pneumonia in Wuhan, China: A descriptive study. Lancet 395, 507-513 (2020). doi:10.1016/S0140-6736(20)30211-7 Medline

15. J. F. Chan, S. Yuan, K.-H. Kok, K. K.-W. To, H. Chu, J. Yang, F. Xing, J. Liu, C. C.-Y. Yip, R. W.-S. Poon, H.-W. Tsoi, S. K.-F. Lo, K.-H. Chan, V. K.-M. Poon, W.-M. Chan, J. D. Ip, J.-P. Cai, V. C.-C. Cheng, H. Chen, C. K.-M. Hui, K.-Y. Yuen, A familial cluster of pneumonia associated with the 2019 novel coronavirus indicating person-toperson transmission: A study of a family cluster. Lancet 395, 514-523 (2020). doi:10.1016/S0140-6736(20)30154-9 Medline

16. J. F. Chan, K.-H. Kok, Z. Zhu, H. Chu, K. K.-W. To, S. Yuan, K.-Y. Yuen, Genomic characterization of the 2019 novel human-pathogenic coronavirus isolated from a patient with atypical pneumonia after visiting Wuhan. Emerg. Microbes Infect. 9, 221-236 (2020). doi:10.1080/222221751.2020.1719902 Medline

17. Coronaviridae Study Group of the International Committee on Taxonomy of Viruses, The species Severe acute respiratory syndrome-related coronavirus: Classifying 2019-nCoV and naming it SARS-CoV-2. Nat. Microbiol. 5, 536-544 (2020). doi:10.1038/s41564-020-0695-z Medline

18. World Health Organization, www.who.int/docs/defaultsource/coronaviruse/situation-reports/20200311-sitrep-51-covid-

19.pdf?sfvrsn=1ba62e57 4.

19. Supporting information is available on Science Online.

20. J. Shi, G. Deng, H. Kong, C. Gu, S. Ma, X. Yin, X. Zeng, P. Cui, Y. Chen, H. Yang, X. Wan, X. Wang, L. Liu, P. Chen, Y. Jiang, J. Liu, Y. Guan, Y. Suzuki, M. Li, Z. Qu, L. Guan, J. Zang, W. Gu, S. Han, Y. Song, Y. Hu, Z. Wang, L. Gu, W. Yang, L. Liang, H. Bao, G. Tian, Y. Li, C. Qiao, L. Jiang, C. Li, Z. Bu, H. Chen, H7N9 virulent mutants detected in chickens in China pose an increased threat to humans. Cell Res. 27, 1409-1421 (2017). doi:10.1038/cr.2017.129 Medline

21. K. J. Stittelaar, L. de Waal, G. van Amerongen, E. J. Veldhuis Kroeze, P. L. Fraaij, C. A. van Baalen, J. J. van Kampen, E. van der Vries, A. D. Osterhaus, R. L. de Swart, Ferrets as a Novel Animal Model for Studying Human Respiratory Syncytial Virus Infections in Immunocompetent and Immunocompromised Hosts. Viruses 8, 168 (2016). doi:10.3390/v8060168 Medline

22. Q. Zhang, J. Shi, G. Deng, J. Guo, X. Zeng, X. He, H. Kong, C. Gu, X. Li, J. Liu, G. Wang, Y. Chen, L. Liu, L. Liang, Y. Li, J. Fan, J. Wang, W. Li, L. Guan, Q. Li, H. Yang, P. Chen, L. Jiang, Y. Guan, X. Xin, Y. Jiang, G. Tian, X. Wang, C. Qiao, C. Li, Z. Bu, H. Chen, H7N9 influenza viruses are transmissible in ferrets by respiratory droplet. Science 341, 410-414 (2013). doi:10.1126/science.1240532 Medline
23. M. Imai, T. Watanabe, M. Hatta, S. C. Das, M. Ozawa, K. Shinya, G. Zhong, A. Hanson, H. Katsura, S. Watanabe, C. Li, E. Kawakami, S. Yamada, M. Kiso, Y. Suzuki, E. A. Maher, G. Neumann, Y. Kawaoka, Experimental adaptation of an influenza H5 HA confers respiratory droplet transmission to a reassortant H5 HA/H1N1 virus in ferrets. Nature 486, 420-428 (2012). doi:10.1038/nature10831 Medline

24. S. Herfst, E. J. A. Schrauwen, M. Linster, S. Chutinimitkul, E. de Wit, V. J. Munster, E. M. Sorrell, T. M. Bestebroer, D. F. Burke, D. J. Smith, G. F. Rimmelzwaan, A. D. M. E. Osterhaus, R. A. M. Fouchier, Airborne transmission of influenza A/H5N1 virus between ferrets. Science 336, 1534-1541 (2012). doi:10.1126/science.1213362 Medline

25. J. M. van den Brand, B. L. Haagmans, L. Leijten, D. van Riel, B. E. E. Martina, A. D. M. E. Osterhaus, T. Kuiken, Pathology of experimental SARS coronavirus infection in cats and ferrets. Vet. Pathol. 45, 551-562 (2008). doi:10.1354/vp.45-4-551 Medline

26. B. E. Martina, B. L. Haagmans, T. Kuiken, R. A. M. Fouchier, G. F. Rimmelzwaan, G. Van Amerongen, J. S. M. Peiris, W. Lim, A. D. M. E. Osterhaus, Virology: SARS virus infection of cats and ferrets. Nature 425, 915 (2003). doi:10.1038/425915a Medline

27. Y. K. Chu, G. D. Ali, F. Jia, Q. Li, D. Kelvin, R. C. Couch, K. S. Harrod, J. A. Hutt, C. Cameron, S. R. Weiss, C. B. Jonsson, The SARS-CoV ferret model in an infectionchallenge study. Virology 374, 151-163 (2008). doi:10.1016/j.virol.2007.12.032 Medline

28. Novel Coronavirus Pneumonia Emergency Response Epidemiology Team, The epidemiological characteristics of an outbreak of 2019 novel coronavirus diseases (COVID-19) in China. [in Chinese] Zhonghua Liu Xing Bing Xue Za Zhi 41, 145-151 (2020). doi:10.3760/cma.jissn.0254-6450.2020.02.003 Medline

29. R. Yan, Y. Zhang, Y. Li, L. Xia, Y. Guo, Q. Zhou, Structural basis for the recognition of SARS-CoV-2 by full-length human ACE2. Science 367, 1444-1448 (2020). doi:10.1126/science.abb2762 Medline

30. M. Letko, A. Marzi, V. Munster, Functional assessment of cell entry and receptor usage for SARS-CoV-2 and other lineage B betacoronaviruses. Nat. Microbiol. 5, 562-569 (2020). doi:10.1038/s41564-020-0688-y Medline

31. The Cell Editorial Team, Embracing the Landscape of Therapeutics. Cell 181, 1-3 (2020). doi:10.1016/i.cell.2020.03.025 Medline

32. Q. Zhang et al., bioRxiv (2020). https://doi.org/10.1101/2020.04.01.021196

33. H. Yang, Y. Chen, C. Qiao, X. He, H. Zhou, Y. Sun, H. Yin, S. Meng, L. Liu, Q. Zhang, H. Kong, C. Gu, C. Li, Z. Bu, Y. Kawaoka, H. Chen, Prevalence, genetics, and transmissibility in ferrets of Eurasian avian-like H1N1 swine influenza viruses. Proc. Natl. Acad. Sci. U.S.A. 113, 392-397 (2016). doi:10.1073/pnas.1522643113 Medline

34. X. Li, J. Shi, J. Guo, G. Deng, Q. Zhang, J. Wang, X. He, K. Wang, J. Chen, Y. Li, J. Fan, H. Kong, C. Gu, Y. Guan, Y. Suzuki, Y. Kawaoka, L. Liu, Y. Jiang, G. Tian, Y. Li, Z. Bu, H. Chen, Genetics, receptor binding property, and transmissibility in mammals of naturally isolated H9N2 Avian Influenza viruses. PLOS Pathog. 10, e1004508 (2014). doi:10.1371/journal.ppat.1004508 Medline

35. D. van Riel, V. J. Munster, E. de Wit, G. F. Rimmelzwaan, R. A. M. Fouchier, A. D. M. E. Osterhaus, T. Kuiken, H5N1 Virus Attachment to Lower Respiratory Tract. Science 312, 399 (2006). doi:10.1126/science.1125548 Medline

\section{ACKNOWLEDGMENTS}

We thank S. Watson for editing the manuscript. Funding: This work was supported by the National Key R\&D Program of China (2020YFC0846500, 2018YFC1200601, 2016YFD0500301). Author contributions: J.S., Z.W., G.Z., H.Y., C.W., B.H., R.L., X.H., L.S., Z.S., Y.Z., P.L., L.L., P.C., J.W., X.Z., and Y.G. performed experiments; J.S., Z.W., G.Z., H.Y., C.W., W.T., G.W., H.C., and Z.B. analyzed data; Z.B. and H.C. designed the study and wrote the manuscript. Competing interests: None of the authors has any competing interests. Data and materials availability: All data are available in the manuscript or the supplementary materials. Sequences of the viruses used in this study have been deposited in GISAID previously with the accession numbers EPI_ISL_402119 and EPI_ISL_408514. Two strains of 2019 novel coronaviruses (C-Tan and F13) were obtained from the China CDC under a material transfer agreement that allows use only in $\mathrm{P} 3+$ or $\mathrm{P} 4$ facilities, prevents live virus sharing and prevents commercial use. This work is licensed under a Creative Commons Attribution 4.0 
International (CC BY 4.0) license, which permits unrestricted use, distribution, and reproduction in any medium, provided the original work is properly cited. To view a copy of this license, visit

https://creativecommons.org/licenses/by/4.0/. This license does not apply to figures/photos/artwork or other content included in the article that is credited to a third party; obtain authorization from the rights holder before using such material.

\section{SUPPLEMENTARY MATERIALS}

science.sciencemag.org/cgi/content/full/science.abb7015/DC1

Materials and Methods

Supplementary Text

Figs. S1 to S10

Table S1

References and Notes (33-35)

MDAR Reproducibility Checklist

View/request a protocol for this paper from Bio-protocol.

12 March 2020; accepted 7 April 2020

Published online 8 April 2020

10.1126/science.abb7015 

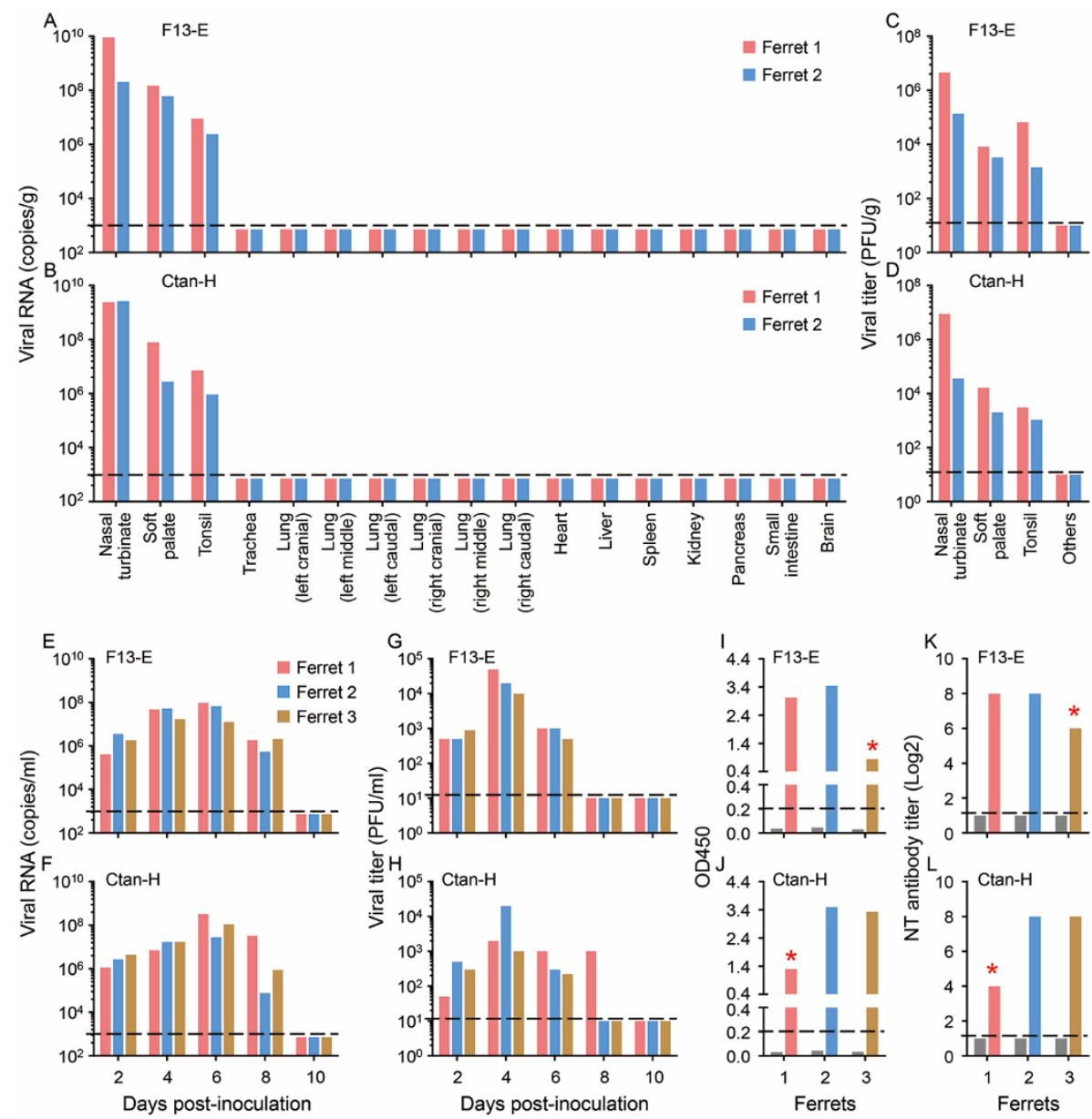

Fig. 1. Replication of SARS-CoV-2 viruses in ferrets. Viral RNA in organs or tissues of ferrets inoculated with (A) F13-E virus or (B) CTan$H$ virus. Viral titers in organs or tissues of ferrets inoculated with F13-E (C) and CTan-H (D). The viral RNA negative organs in panels A and B were also virus titration negative, which were indicated as "Others" in panels $C$ and $D$. Viral RNA ( $E$ and $F$ ) and viral titer $(G$ and $H$ ) in nasal washes of ferrets inoculated with $\mathrm{F} 13-\mathrm{E}(\mathrm{E}, \mathrm{G})$ and $\mathrm{CTan}-\mathrm{H}(\mathrm{F}, \mathrm{H})$. Antibodies against SARS-CoV-2 tested by an ELISA ( $\mathrm{I}$ and $\mathrm{J}$ ) and neutralization assay ( $K$ and $L$ ) with the sera derived from ferrets inoculated with F13-E (I, K) and CTan-H (J, L). Each color bar represents the value from an individual animal. The gray bars in the panels $I$ to $L$ indicate the antibody values of sera collected from each animal before the virus was inoculated. Asterisks indicate animals that were euthanized on day 13 after virus inoculation, the other four animals were euthanized on day 20 p.i. The horizontal dashed lines in the panels I and $L$ show the cutoff value for seroconversion, and the horizontal dashed lines in other panels indicate the lower limit of detection. 

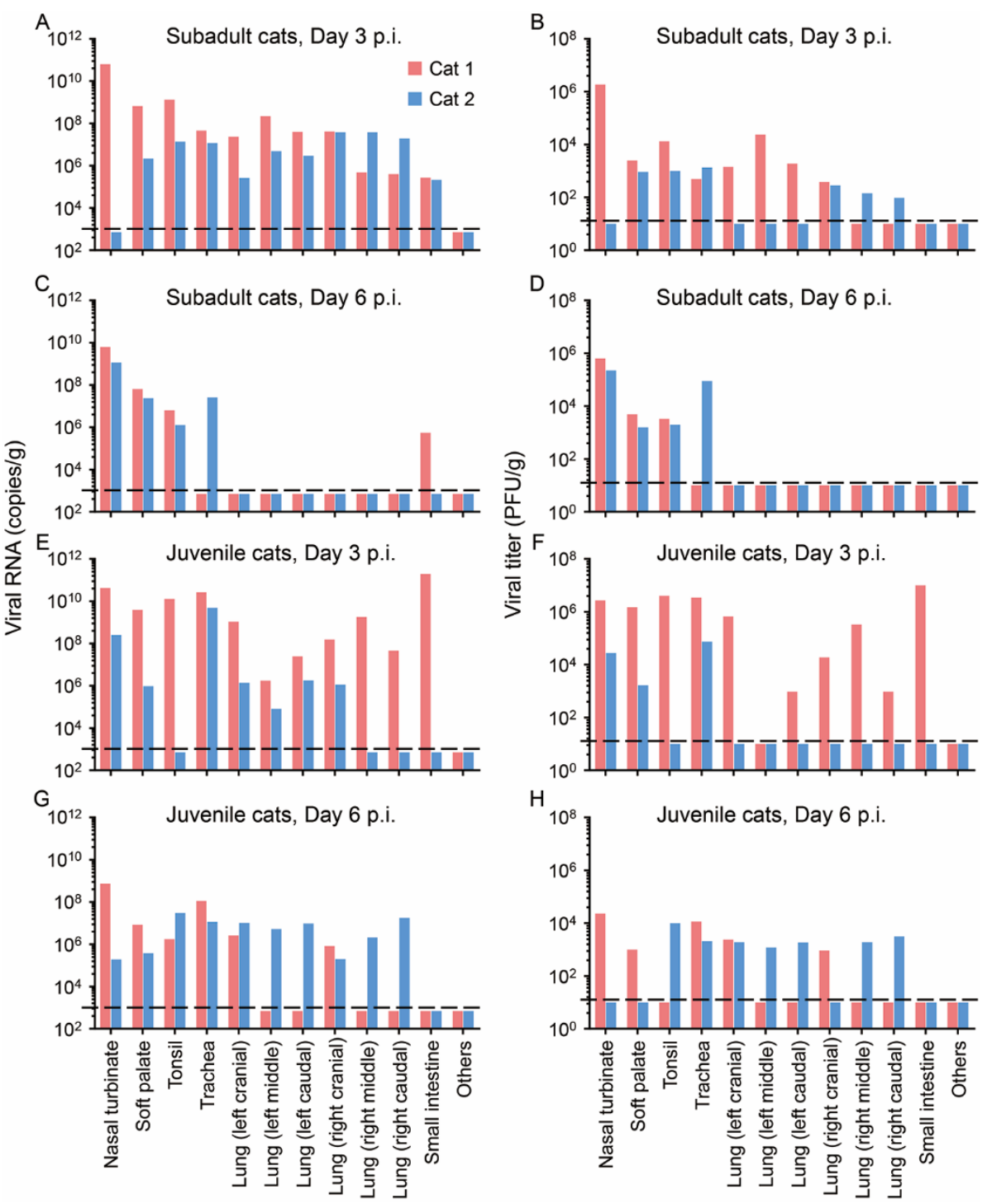

Fig. 2. Replication of SARS-CoV-2 in cats. Subadult cats and juvenile cats inoculated with $\mathrm{CTan}-\mathrm{H}$ virus were euthanized on day 3 postinoculation (p.i.) and day 6 p.i., and their organs were collected for viral RNA detection and virus titration. (A) Viral RNA and (B) viral titers of subadult cats on day 3 p.i. (C) Viral RNA and (D) viral titers of subadult cats on day 6 p.i. (E) Viral RNA and (F) viral titers of juvenile cats on day 3 p.i., the values of red bars in panels $E$ and $F$ are from the cat that died on this day. $(G)$ Viral RNA and $(H)$ viral titers of juvenile cats on day 6 p.i. Others: viral negative organs, including brain, heart, submaxillary lymph nodes, kidneys, spleen, liver, and pancreas. Each color bar represents the value from an individual animal. The horizontal dashed lines indicate the lower limit of detection. 

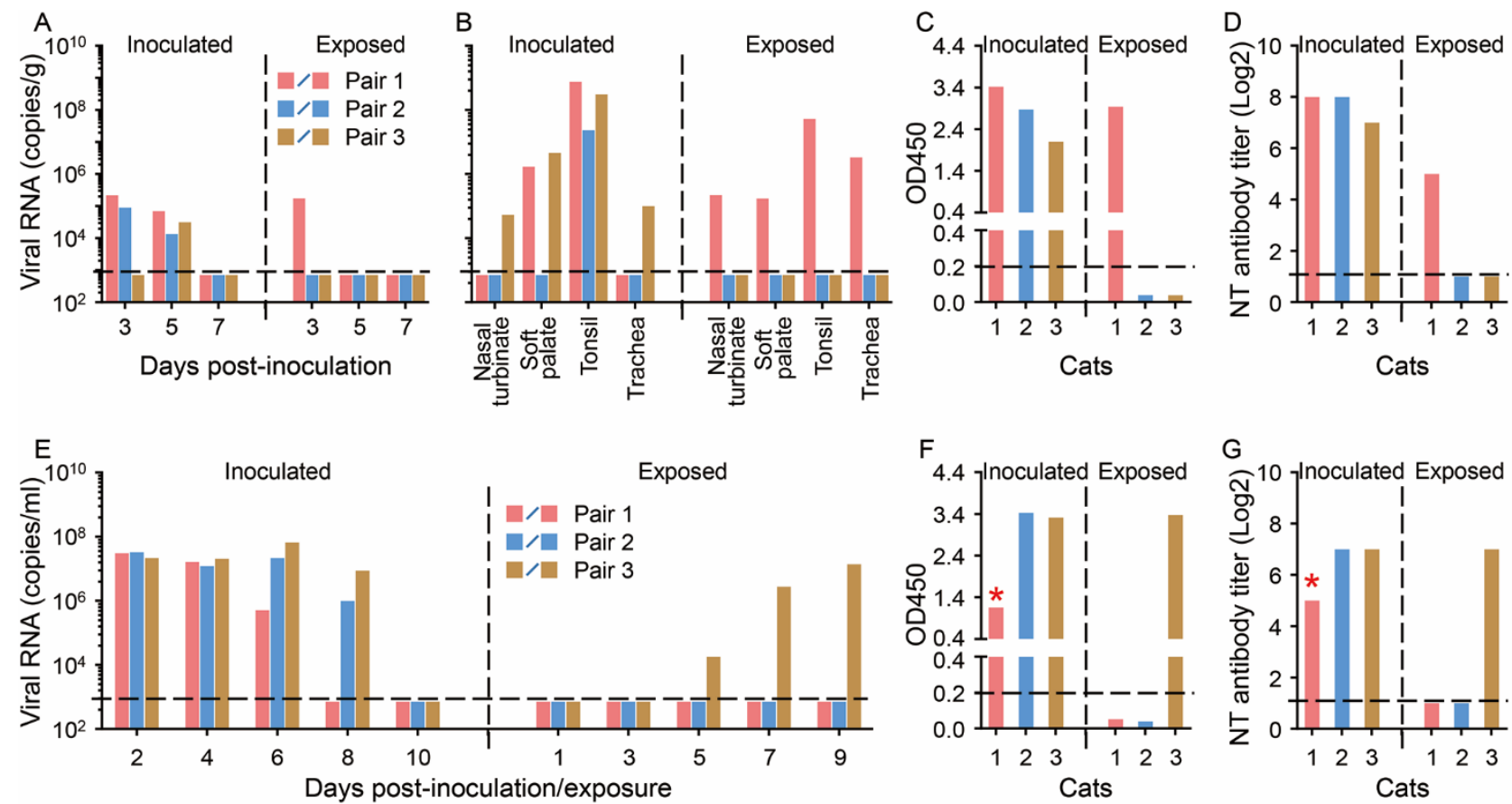

Fig. 3. Transmission of SARS-CoV-2 in cats. Transmission of CTan-H virus was evaluated in subadult cats (A to D) and juvenile cats (E to $G$ ). (A) Viral RNA in the feces of virus inoculated or exposed subadult cats. (B) Viral RNA in tissues or organs of virus inoculated or exposed subadult cats that were euthanized on day 11 p.i. (pair one, red bars) or on day 12 p.i. (pair 2 and pair 3). Antibodies against SARS-CoV-2 of these euthanized subadult cats were detected by using an ELISA (C) and neutralization assay (D). (E) Viral RNA in nasal washes of juvenile cats. Sera of the juvenile cats were collected on day 20 p.i., except for one virus inoculated animal died on day 13 p.i. and the antibody values of this cat (indicated by asterisks) were detected from the sera collected on day 10 p.i., their antibodies against SARS-CoV-2 were detected by using an ELISA (F) and neutralization assay (G). Each color bar represents the value from an individual animal. The horizontal dashed lines in the panels $\mathrm{C}$ and $\mathrm{F}$ show the cutoff value for seroconversion, and the horizontal dashed lines in other panels indicate the lower limit of detection. 
Table 1. Susceptibility of dogs, pigs, chickens, and ducks to SARS-CoV-2a.

Viral RNA detection in animals inoculated with

SARS-CoV-2 isolate CTan-H;

no. of positive/total (copies, $\log _{10}$ )

\begin{tabular}{|c|c|c|c|c|c|c|c|c|c|c|}
\hline \multirow{3}{*}{ Animal } & \multirow{3}{*}{ Treatment } & \multicolumn{8}{|c|}{ no. of positive/total (copies, $\log _{10}$ ) } & \multirow{3}{*}{$\begin{array}{c}\text { Seroconversion } \\
\text { No. of } \\
\text { positive/totalc }\end{array}$} \\
\hline & & \multicolumn{4}{|c|}{ Oropharyngeal swab } & \multicolumn{4}{|c|}{ Rectal swab } & \\
\hline & & $\begin{array}{c}\text { Day } 2 \\
\text { p.i. }\end{array}$ & $\begin{array}{c}\text { Day } 4 \\
\text { p.i. }\end{array}$ & $\begin{array}{c}\text { Day } 6 \\
\text { p.i. }\end{array}$ & $\begin{array}{c}\text { Other } \\
\text { timepoints }\end{array}$ & $\begin{array}{c}\text { Day } 2 \\
\text { p.i. }\end{array}$ & $\begin{array}{c}\text { Day } 4 \\
\text { p.i. }\end{array}$ & $\begin{array}{c}\text { Day } 6 \\
\text { p.i. }\end{array}$ & $\begin{array}{c}\text { Other } \\
\text { timepoints }\end{array}$ & \\
\hline \multirow{2}{*}{ Dog $^{b}$} & Inoculated & $0 / 5$ & $0 / 5$ & $0 / 4$ & $0 / 4$ & $\begin{array}{c}2 / 5 \\
(6.5,5.4)\end{array}$ & $0 / 5$ & $\begin{array}{c}1 / 4 \\
(4.2)\end{array}$ & $0 / 4$ & $2 / 4$ \\
\hline & Contact & $0 / 2$ & $0 / 2$ & $0 / 2$ & $0 / 2$ & $0 / 2$ & $0 / 2$ & $0 / 2$ & $0 / 2$ & $0 / 2$ \\
\hline \multirow{2}{*}{ Pig } & Inoculated & $0 / 5$ & $0 / 5$ & $0 / 5$ & $0 / 5$ & $0 / 5$ & $0 / 5$ & $0 / 5$ & $0 / 5$ & $0 / 5$ \\
\hline & Contact & $0 / 3$ & $0 / 3$ & $0 / 3$ & $0 / 3$ & $0 / 3$ & $0 / 3$ & $0 / 3$ & $0 / 3$ & $0 / 3$ \\
\hline \multirow{2}{*}{ Chicken } & Inoculated & $0 / 5$ & $0 / 5$ & $0 / 5$ & $0 / 5$ & $0 / 5$ & $0 / 5$ & $0 / 5$ & $0 / 5$ & $0 / 5$ \\
\hline & Contact & $0 / 3$ & $0 / 3$ & $0 / 3$ & $0 / 3$ & $0 / 3$ & $0 / 3$ & $0 / 3$ & $0 / 3$ & $0 / 3$ \\
\hline \multirow{2}{*}{ Duck } & Inoculated & $0 / 5$ & $0 / 5$ & $0 / 5$ & $0 / 5$ & $0 / 5$ & $0 / 5$ & $0 / 5$ & $0 / 5$ & $0 / 5$ \\
\hline & Contact & $0 / 3$ & $0 / 3$ & $0 / 3$ & $0 / 3$ & $0 / 3$ & $0 / 3$ & $0 / 3$ & $0 / 3$ & $0 / 3$ \\
\hline
\end{tabular}

animals were intranasally inoculated with $10^{5} \mathrm{PFU}$ (dogs and pigs) or $10^{4.5} \mathrm{PFU}$ (chickens and ducks) of the CTan-H virus, and two (beagles) or three (pigs, chickens, and ducks) uninfected animals were housed in the same room with their infected counterparts to monitor the transmission of the CTan-H virus. Oropharyngeal and rectal swabs from all animals were collected on the indicated days post inoculation (p.i.) for viral RNA detection. Other timepoints include days $8,10,12$, and 14 p.i..

'One virus-inoculated beagle was euthanized on day 4 p.i., but viral RNA was not detected in any of its collected organs, which included lung, trachea, nasal turbinate, soft palate, brain, heart, tonsil, kidneys, spleen, liver, pancreas, and small intestine (fig. S6).

'Sera were collected from all animals on day 14 p.i., and antibodies against SARS-CoV-2 were detected by using a Double Antigen Sandwich ELISA kit (ProtTech, Luoyang, China). 